Running title: Metacommunity ecology and biogeography of aquatic organisms

\title{
Metacommunity ecology meets biogeography: effects of geographical region, spatial dynamics and environmental filtering on community structure in aquatic organisms
}

Jani Heino ${ }^{1}$, Janne Soininen ${ }^{2}$, Janne Alahuhta ${ }^{3,4}$, Jyrki Lappalainen ${ }^{5}$ and Risto Virtanen ${ }^{6,7,8}$

${ }^{1}$ Finnish Environment Institute, Natural Environment Centre, Biodiversity, P.O. Box 413, FI90014 Oulu, Finland.

${ }^{2}$ University of Helsinki, Department of Geosciences and Geography, P.O. Box 64, FI-00014 University of Helsinki, Finland.

${ }^{3}$ University of Oulu, Geography Research Unit, P.O. Box 3000, FI-90014 University of Oulu, Finland.

${ }^{4}$ Finnish Environment Institute, Freshwater Centre, State of Surface Waters, P.O. Box 413, FI-90014 Oulu, Finland
${ }^{5}$ University of Helsinki, Department of Environmental Sciences, P.O. Box 65, FI-00014, University of Helsinki, Finland.

${ }^{6}$ Department of Physiological Diversity, Helmholtz Center for Environmental Research UFZ, Permoserstr. 15, Leipzig 04318, Germany.

${ }^{7}$ German Centre for Integrative Biodiversity Research (iDiv) Halle-Jena-Leipzig, Deutscher Platz 5e, Leipzig D-04103, Germany.

${ }^{8}$ Department of Ecology, University of Oulu, PO Box 3000, FI-90014 University of Oulu, Finland.

Correspondence to J. Heino: Finnish Environment Institute, Paavo Havaksen Tie 3, FI-90014 Oulu, Finland. E-mail: jani.heino@environment.fi.

Author contribution statement. All authors devised the ideas and provided data. JH ran the statistical analyses and led the writing. All authors commented on the manuscript drafts. 
28 Abstract. We examined variation in the composition of six freshwater organismal groups across various drainage basins in Finland. We first modelled spatial structures within each drainage basin using Moran eigenvector maps. Second, we partitioned variation in community structure among three groups of predictors using constrained ordination: (1) local environmental variables, (2) spatial variables, and (3) dummy variable drainage basin identity. Third, we examined turnover and nestedness components of multiple-site beta diversity, and tested the best fit patterns of our datasets using the "elements of metacommunity structure" analysis. Our results showed that basin identity and local environmental variables were significant predictors of community structure, whereas withinbasin spatial effects were typically negligible. In half of the organismal groups (diatoms, bryophytes, zooplankton), basin identity was a slightly better predictor of community structure than local environmental variables, whereas the opposite was true for the remaining three organismal groups (insects, macrophytes, fish). Both pure basin and local environmental fractions were, however, significant after accounting for the effects of the other predictor variable sets. All organismal groups exhibited high levels of beta diversity, which was mostly attributable to the turnover component. Our results showed consistent Clementsian type metacommunity structures, suggesting that subgroups of species responded similarly to environmental factors or drainage basin limits. We conclude that aquatic communities across large scales are mostly determined by environmental and basin effects, which leads to high beta diversity and prevalence of Clementsian community types.

Keywords. Bryophytes, diatoms, fish, invertebrates, lakes, macrophytes, metacommunities, streams. 


\section{Introduction}

53 Biogeography and community ecology are two disciplines that combine history, dispersal,

54 biotic interactions and environmental filtering as determinants of the structure of biotic

55 assemblages. However, a better understanding of the determinants of biotic assemblages

56 might benefit from a closer conceptual unification of these disciplines (Jenkins and Ricklefs

57 2011; Ricklefs and Jenkins 2011). Biotic assemblages can be understood to comprise either

58 regional biotas or local communities, depending on the grain size under investigation (Beck

59 et al. 2012; Pinel-Alloul et al. 2013). One means to investigate biogeographic and ecological

60 influences is to compare the effects of regional, spatial and environmental drivers of local

61 communities over large spatial extents (Shurin et al. 2009; Bini et al. 2014; Gonçalves-Souza

62 et al. 2014).

A major aim of biogeography is to consider evolutionary, historical and climatic

64 influences on regional biotas. One typically finds a strong relationship between present-day climate and species richness (e.g. Hawkins and Porter 2003) or composition (e.g. Heino and Alahuhta 2015) of regional biotas. The same is true for historical effects on regional biotas,

67 which can be investigated as phylogenetic patterns (e.g. Wiens 2012) or using various

68 statistical approaches as proxies of historical effects (e.g. Hortal et al. 2011). The degree to

69 which the influences of these broad-scale factors remain important when the focus is on local

70 communities is still elusive. Some studies have suggested that regional and historical

71 influences remain significant even when the focus is on local communities (Hoeinghaus et al.

72 2007; Vyverman et al. 2007), but others have shown that local environmental factors account

73 for significant variation in local community structure even over broad spatial extents (Van

74 der Gucht et al. 2007; Gonçalves-Souza et al. 2014; Souffreau et al. 2015). The influence of 
regional characteristics on local communities can be studied as an overall "region effect" on local communities (Fig. 1), and it indirectly relates to historical effects and climatic forcing on local community structure (Declerck et al. 2011; Viana et al. 2015).

Metacommunity ecology is a recently emerged subdiscipline of ecology, where dispersal among sites is considered a key to understand biotic assemblages (Leibold et al. 2004; Jocque et al. 2010). Metacommunity ecology emphasises the idea that dispersal among sites within a region is an important process affecting the structure of local communities (Leibold et al. 2004). Dispersal may be limiting or homogenizing local communities, the effects of which may not be easily distinguishable because both may induce spatial structuring in the biological data (e.g. Ng et al. 2009). However, those effects can be at least partly separated by focusing on nested spatial scales (Declerck et al. 2011; Silva and Hernándes 2015), where differences among regions may denote dispersal limitation and spatial structures within a region mainly relate to homogenising effects of dispersal that can happen via mass effects (e.g. Mouquet and Loreau 2003). For freshwater organisms, regions can be individual drainage basins (e.g. Heino 2011), whereby dispersal is more likely to take place within such regions than between regions (e.g. Heino et al. 2015a). Regions could also be delineated based on drainage basin boundaries, major landscape configurations or ecoregions in terrestrial studies.

Metacommunity theory also predicts that species sorting, i.e. filtering of species by local abiotic and biotic factors, is most pronounced when dispersal rates are intermediate (Leibold et al. 2004). Such intermediate dispersal allows species to track variation in environmental conditions among sites within a region (e.g. a drainage basin), resulting in a relatively good match between environmental conditions and community structure (Leibold et al. 2004). True species sorting may be disrupted by both limiting and high dispersal rates (Ng et al. 2009; Winegardner et al. 2012), although understanding their relative importance 
may be masked by spatially-structured environmental variation (Pinel-Alloul et al. 1995;

Heino et al. 2015a). Spatially-autocorrelated environmental variables are a typical phenomenon in observational studies, often making it difficult to infer the relative roles of species sorting and dispersal effects on community structure (Pinel-Alloul et al. 1995; Bonada et al. 2012; Heino et al. 2015b). Hence, heuristic approaches across different scales should be used to disentangle those effects on community structure.

In addition to explaining variation in local community structure, a major aim of both biogeography and metacommunity ecology is to quantify the degree of variation (e.g. beta diversity, Baselga 2010) or describe predominant patterns (e.g. elements of metacommunity structure, Leibold and Mikkelson 2002) in biological survey data. While beta diversity has been quantified at various spatial grains and extents (Soininen et al. 2007, Anderson et al. 2011), the elements of metacommunity structure have mostly been tested using data from local communities within relatively small regions (Leibold and Mikkelson 2002; Heino et al. 2015c; but see Presley and Willig 2010; Meynard et al. 2013). Recently, Heino and Alahuhta (2015) applied the elements of metacommunity structure approach to encompass large spatial grain and geographical extent. They found, as opposed to sets of local communities within small regions where various patterns are typically detected (Heino et al. 2015c; Tonkin et al. 2015a), that regional beetle faunas across a broad geographical gradient showed consistent Clementsian type variation (Heino and Alahuhta 2015). Clementsian type variation emphasises discrete 'community types' along ecological gradients, such that subgroups of species replace other subgroups in space (Clements 1936). Such variation also suggests that subgroups of species either responded similarly to environmental variation or are affected by similar historical effects (Heino and Alahuhta 2015; Tonkin et al. 2015b). We here expanded this approach from single drainage basins to encompass local communities of six aquatic organismal groups surveyed across three drainage basins. 

metacommunity organization (Cottenie 2005; Van der Gucht et al. 2007). Such patterns have been found in many stream (Göthe et al. 2013; Grönroos et al. 2013; Tonkin et al. 2015b) and lake studies (Soininen et al. 2011; Alahuhta and Heino 2013; Heino 2013). Second, we expected that basin identity and its associated biogeographical and climatic aspects, would show the strongest effect on variation in community structure. This is because biogeographical factors, including regional variation in climate, should be most important at large spatial extents (Gonçalves-Souza et al. 2014; Viana et al. 2015). We had data for three groups of organisms surveyed in streams (i.e. diatoms, bryophytes, insects) and three groups of organisms surveyed in lakes (i.e. macrophytes, zooplankton, fish). These organismal groups show wide variation in ecological and biological characteristics, including life form, body size and dispersal mode (Heino et al. 2015c). Hence, we examined whether different organismal groups would show different patterns, with (a) lake organisms being more dispersal limited than stream organisms, the communities of the latter which are better connected by dispersal that those of the former, (b) passively dispersing organisms with small propagules (i.e. diatoms, bryophytes, macrophytes, zooplankton) showing less biogeographical variation than more actively dispersing large organisms (i.e. insects, fish), and (c) passively dispersing organisms should show stronger environmental control than actively dispersing organisms across the biogeographical scales of the three drainage basins. This is because small passively dispersing organisms (e.g. diatoms), which can disperse passively via air and animal vectors (Kristiansen 1996), may overcome drainage basin boundaries more easily than actively dispersing organisms restricted to dispersal via watercourses (De Bie et al. 2012). We also examined whether Clementsian metacommunity structures and high beta diversity would be evident for all organismal groups because our 
surveys comprised relatively large geographical and environmental gradients (Heino and Alahuhta 2015; Tonkin et al. 2015b). streams (e.g. Grönroos et al. 2013) and lakes (e.g. Soininen et al. 2011). Our present study provides new comparative information about the responses of different aquatic organismal groups to region identity, within-region spatial structuring and local environmental factors. conducted within smaller geographic regions (e.g. Heino et al. 2015c).

Materials and Methods

\section{Dataset characteristics and environmental variables}

We re-analysed some of our recently-collected data (Soininen et al. 2009; 2011; Grönroos et al. 2013; Alahuhta et al. 2012; 2015; Heino et al. 2015c) for three groups of stream organisms (i.e. diatoms, bryophytes, insects) and three groups of lake organisms (i.e. macrophytes, zooplankton, fish). However, in this study, we combined data such that they comprised 45 to 60 sites across three drainage basins to facilitate comparative purposes. In all cases, datasets were carefully taxonomically harmonised to guarantee that they were comparable. The three drainage basins and sites surveyed generally differed between the organismal groups (Fig. 2), drains into the sea (i.e. Arctic Ocean, White Sea or Baltic Sea). Due to limited resources, sites 
were sometimes sampled in different years to avoid large seasonal variation. Moreover, our experience on northern freshwaters has shown that between-year variation is likely to be less pronounced than between-season variation.

\section{Stream diatoms}

We sampled 45 stream sites across three drainage basins in Finland. The drainage systems were: (1) Koutajoki (centered on $\left.66^{\circ} \mathrm{N}, 29^{\circ} \mathrm{E}\right)$, (2) Kemijoki $\left(67^{\circ} \mathrm{N}, 28^{\circ} \mathrm{E}\right)$, and (3) Muonionjoki $\left(68^{\circ} \mathrm{N}, 24^{\circ} \mathrm{E}\right)$. The spatial extent (a rectangle encompassing all study sites) comprising the three study areas was $63,609 \mathrm{~km}^{2}$. Generally, 15 sites per region appeared to be a sufficient sample size, detecting the majority of the diatom species present in the regional species pool of a drainage basin (Soininen et al. 2009). Algal sampling was conducted once for each site during summer low-flows in August 2001 or 2004. Sampling was confined to near-pristine streams. All sampling was conducted by the same field crew using a strictly standardized field protocol. Each study site with a length of $10 \mathrm{~m}$ was divided into 5 or 10 cross-stream transects, depending on stream width. One or two stones were selected randomly in each transect, and diatoms were scraped off the stones from a predefined area $\left(3.1 \mathrm{~cm}^{2}\right)$, using a rubber template. Subsamples, 10 in total, were then pooled into a composite sample for each site. In the laboratory, fresh samples were carefully checked to guarantee that most diatom frustules were alive before acid combustion. We used acid combustion $\left(\mathrm{HNO}_{3}: \mathrm{H}_{2} \mathrm{SO}_{4}, 2: 1\right)$ to clean frustules of organic material. Cleaned diatoms were mounted in Naphrax and a total of 500 frustules per sample were identified and counted, using phase-contrast light microscopy (magnification 1000x) (for details, see Soininen et al. 2009). In total, $96 \%$ of diatoms were identified to species. We also measured current velocity, 
shading, particle size, moss cover, conductivity and $\mathrm{pH}$ in the field, and analyzed water samples for water colour and total phosphorus in the laboratory.

\section{Stream bryophytes}

Stream bryophytes were sampled at the same 45 sites as diatoms using a systematic sampling protocol. At each stream site, $1050 \times 50 \mathrm{~cm}$ plots were studied. The plots were placed at regular intervals of $2 \mathrm{~m}$ along the approximately $20 \mathrm{~m}$ long riffle section. The order of sampling proceeded from the stream margin to the center of the stream to cover habitat variation in the riffle section. Bryophytes were either identified in the field or samples of difficult-to-identify bryophytes were taken to laboratory for microscopic identification. Bryophytes were identified to species except for thalloid liverworts of genus Pellia.

\section{Stream insects}

We sampled 60 near-pristine to pristine streams across three drainage basins in Finland (Grönroos et al., 2013). Each drainage basin had 20 sampled streams. The drainage basins were Iijoki (centered on $65^{\circ} \mathrm{N}, 27^{\circ} \mathrm{E}$ ), Koutajoki (centered on $66^{\circ} \mathrm{N}, 29^{\circ} \mathrm{E}$ ) and Tenojoki (centered on $70^{\circ} \mathrm{N}, 27^{\circ} \mathrm{E}$ ). The spatial extent comprising the three study areas was 87,101 $\mathrm{km}^{2}$. Stream macroinvertebrates were sampled in the lijoki drainage basin in the last week of May in 2009, in the Koutajoki drainage basin in the last week of May in 2008, and in the Tenojoki drainage basin in the second week of June in 2010. At each site, the field crew took a collective two-minute kicknet (net mesh size $0.3 \mathrm{~mm}$ ) sample covering most microhabitats present in a riffle site (for details, see Grönroos et al. 2013). In total, 79\% of insects were identified to species in the laboratory. Several riparian, in-stream habitat and water chemistry variables were also measured at each site (Grönroos et al., 2013). Cover (\%) of deciduous 
trees was assessed in a 50-meter section on both banks upstream of each sampling site.

Shading was estimated visually as percent canopy cover at the whole study section. Current velocity (at $0.6 \times$ depth) and depth were measured at 30 random locations along cross-stream transects, the number of which depended on stream width. More transects were sampled in narrow than wide streams. Mean wetted width of each stream reach was measured based on five cross-stream transects. Macrophyte cover (\%) and substratum particle class cover (\%) were assessed at 10 random randomly-spaced $50 \mathrm{~cm} \times 50 \mathrm{~cm}$ plots. In addition, in each of the 10 plots, visual estimates of the percentage cover of five particle size classes were made based on a modified Wentworth scale (see Grönroos et al. 2013). Water samples were collected simultaneously with the field sampling and were measured for $\mathrm{pH}$ and conductivity.

\section{Lake macrophytes}

Macrophytes were sampled in 57 lakes with variable environmental conditions in three drainage basins in Finland (Alahuhta et al. 2015). In each of the Kymijoki $\left(62^{\circ} \mathrm{N}, 26^{\circ} \mathrm{E}\right)$ and Vuoksi $\left(63^{\circ} \mathrm{N}, 2^{\circ} \mathrm{N}\right)$ drainage basins, 20 lakes were surveyed, whereas 17 lakes were investigated in the Kokemäki drainage basin $\left(62^{\circ} \mathrm{N}, 24^{\circ} \mathrm{N}\right)$. The spatial extent comprising the three study areas was $132,060 \mathrm{~km}^{2}$. Lake macrophyte surveys were carried out during growing seasons between 2002 and 2008 in the Kymijoki and Vuoksi drainage basins, and between 2000 and 2011 in the Kokemäki drainage basin. Vascular plants, including helophytes and hydrophytes, were sampled using a main belt transect method, in which a varying number of 5-meter wide transects, depending on lake size, from the upper eulittoral to the outer limit of vegetation were examined. All macrophytes were identified to species. Ten hydro-morphological and water quality variables known to be important for aquatic plants were measured in each lake (Alahuhta et al. 2015). These variables consisted of lake 
altitude, lake area, lake perimeter, alkalinity, turbidity, colour, Secchi depth, total phosphorus, total nitrogen and conductivity. Water quality variables represented median values for surface samples during the growing season over the period between 2000 and 2007 for the Kymijoki and Vuoksi drainage basins, and between 2000 and 2011 for the Kokemäenjoki drainage basin. Water quality data was obtained from the Hertta database maintained by the Finnish Environment Institute (www.environment.fi).

\section{Lake zooplankton}

Zooplankton were sampled from 60 small lakes in Finland during July in 2008 or 2009. The sites were sampled in three drainage basins. We sampled 20 lakes both in the Kokemäenjoki $\left(61^{\circ} \mathrm{N}, 24^{\circ} \mathrm{E}\right)$ and the Kymijoki $\left(63^{\circ} \mathrm{N}, 25^{\circ} \mathrm{E}\right)$ drainage basins in 2008 , and 20 lakes in the Koutajoki $\left(66^{\circ} \mathrm{N}\right.$ and $\left.29^{\circ} \mathrm{E}\right)$ drainage basin in 2009 . These drainage basins were chosen because they cover a relatively large geographical extent and because the nutrient concentrations of lakes vary from ultraoligotrophic to eutrophic (Soininen et al. 2011). The spatial extent comprising the three study areas was $125,190 \mathrm{~km}^{2}$. We sampled only small lakes to ensure that plankton sampling covers the site as adequately as possible. Most of the lakes within the drainage basins were not readily inter-connected to each other via water routes. For more information on the environmental characteristics of the lakes within the drainage basins, see Soininen et al. (2011). Plankton samples were collected with a tube sampler $(\mathrm{V}=2.3 \mathrm{~L})$ from three locations in the middle of the lake and pooled. We collected the samples in the middle of the lakes in order to avoid benthic taxa from the littoral entering the samples. The samples were collected at $0.5 \mathrm{~m}$ below the surface of the water.

Zooplankton samples $(6.15 \mathrm{~L})$ were filtered through a $50 \mu \mathrm{m}$ net and preserved with formaldehyde in the field. The maximum depth of the lakes as well as surface water 
temperature was measured. The surface area of each lake was measured using Geographic Information System (MapInfo Version 6.5, MapInfo, Troy, NY, USA). Conductivity was measured in the field using a conductivity meter (Philips PW 9529). Samples for water chemistry analyses were collected simultaneously with the plankton sampling and analyzed in the laboratory for chlorophyll $a$, water colour, total nitrogen, and total phosphorus. In the laboratory, all zooplankton individuals were counted at magnification of $125-400 \times$ using an inverted microscope. Both crustacean zooplankton and rotifers were included in the counting. A total of $71 \%$ of zooplankton were identified to species.

\section{Lake fishes}

The lake fish data were based on postal inquiries sent to persons employed as chairmen or active members in regional fishing associations (Lappalainen and Malinen 2002). All fish were identified to species. The data were from three drainage basins: Vuoksi (centered on $63^{\circ} \mathrm{N}, 28^{\circ} \mathrm{E}$ ), Kymijoki (centered on $62^{\circ} \mathrm{N}, 26^{\circ} \mathrm{E}$ ) and Kokemäenjoki (centered on $61^{\circ} \mathrm{N}$, $\left.24^{\circ} \mathrm{E}\right)$. From each of the three drainage basins, 20 lakes were randomly selected for this study. The spatial extent comprising the three study areas was $150,869 \mathrm{~km}^{2}$. The environmental data of the lakes were based on the Hertta database (www.environment.fi). The environmental variables available were lake area, length of the shoreline, altitude, maximum lake depth, conductivity, $\mathrm{pH}$, colour and total phosphorus. Average values of water chemistry incorporating the whole water column for a period between June and September were calculated.

\section{Spatial analysis}


We used Moran's eigenvector maps to model spatial structures among the sites within drainage basins and to provide spatial variables for community modelling (Borcard and Legendre 2002; Legendre and Legendre 2012). We thus obtained multiple spatial variables derived from geographical coordinates using Moran's eigenvector maps (MEM). These variables describe spatial patterns in communities (Dray et al. 2012). In practice, this spatial analysis generated orthogonal spatial variables based on information about geographic coordinates, number of basins (i.e. blocks) and sites within each basin (Borcard et al. 2011; Declerk et al. 2011). Hence, as input data, we had site coordinates and indicated, in the R script, which sites to belong to which basin. Otherwise, the MEM analysis resembles that of the original MEM analysis without blocks. These multiple spatial variables describe withinbasin spatial structures in the data, such that the sites in the other two basins get zero values when the spatial structures within a focal basin are considered (Declerck et al. 2011; Silva and Hernández 2015). This analysis results in a staggered matrix of MEM eigenvectors, i.e., within-region spatial variables. These variables are efficient in modelling spatial structures of community composition data at multiple scales within each basin. Large-scale spatial structures among drainage basins were modelled by a dummy variable "basin identity" because Moran eigenvector maps do not work well when there are large gaps between regions, such as those between our drainage basins. The Moran's eigenvector maps analysis was run using the function "create.MEM.model” (see Declerk et al. 2011). connected by streams, we could not use more sophisticated methods taking into account hydrological connections among sites (Blanchet et al. 2008; Borcard et al. 2011; Liu et al. 2013). Also, it has been previously shown for stream organisms that MEM eigenvectors based on either overland or watercourse distances between sites provide similar information about spatial effects on community structure (Landeiro et al. 2011; Grönroos et al. 2013). 
Finally, it should be noted that the spatial component in variation partitioning analyses should

317 be considered with certain caution (Gilbert and Bennet 2010; Smith and Lundholm 2010), and that large gradients in community composition may be challenging to model because of multiple changes in community composition (Tuomisto et al. 2012).

\section{Forward selection of explanatory variables}

The final sets of environmental and spatial variables were separately selected for the redundancy analysis (RDA; Rao 1964) models using a forward selection procedure with two stopping rules (Blanchet et al. 2008). Forward selection proceeds only if the global model, which is tested first, is significant. The first stopping rule entails exceeding the critical pvalue $(\alpha=0.05)$, and the second is related to the reduced model adjusted $R^{2}$ value exceeding that of the global model.

\section{Variation partitioning}

We used the raw data approach (i.e. site-by-species matrix as response) to examine variation in community structure among sites (Legendre et al. 2005; Anderson et al. 2011) in each of the six datasets. Each dataset comprised all sites in all three drainage basins. We used redundancy analysis (RDA, Rao 1964) to analyse variation in presence-absence data, as comparable abundance data were not available for all organismal groups. RDA examines variation in species composition $(\mathbf{Y})$ in relation to sets of predictor variables that were in our present study environmental variables $(\mathbf{E})$, spatial variables $(\mathbf{S})$ derived from Moran's 
eigenvector map analysis (see above) and dummy variable basin (B). Prior to the RDA, siteby-species presence-absence data were Hellinger-transformed to make the data better analysable using linear methods (Legendre and Gallagher 2001) and because Hellinger transformation/Hellinger distance was deemed highly suitable for community composition data in a comparative analysis (Legendre and de Caceres 2013). The Hellinger transformation consists in transforming the site-by-species data into relative values per site, by dividing each value by the site sum, then taking the square root of the resulting values. Hellinger transformation can be used for both presence-absence and abundance data (Legendre et al. 2005). We selected significant variables in the final RDA models of each set of variables (E or S) using the forward selection method with two stopping rules (Blanchet et al. 2008) with the function "ordiR2step" in the R package vegan (Oksanen et al. 2013). We used redundancy analysis (RDA) to partition variation in species composition $(\mathbf{Y})$ between $\mathbf{E}, \mathbf{S}$ and $\mathbf{B}$ following the widely-used variation partitioning approach (Borcard et al. 1992; Legendre and Legendre 2012). Variation partitioning of species composition (Y) between three sets of predictor variables results in pure environment $(\mathbf{E} \mid \mathbf{S}+\mathbf{B})$, pure spatial $(\mathbf{S} \mid \mathbf{E}+\mathbf{B})$ and pure basin $(\mathbf{B} \mid \mathbf{E}+\mathbf{S})$ fractions, as well as their shared effects and unexplained variance (U). In many cases, spatial variables were not significant, and we thus ran the variation partitioning between $\mathbf{E}$ and $\mathbf{B}$ only. Variation partitioning was run using the function "varpart" in the $\mathrm{R}$ package vegan. We reported adjusted $\mathrm{R}^{2}$ values in all analyses because they are unbiased estimates of explained variation (Peres-Neto et al. 2006). We also tested for the significance of the total $\mathbf{E}, \mathbf{S}$ and $\mathbf{B}$ fractions, and pure fractions $\mathbf{E}|\mathbf{S}+\mathbf{B}, \mathbf{S}| \mathbf{E}+\mathbf{B}$ and $\mathbf{B} \mid \mathbf{E}+\mathbf{S}$ using the function "anova" in the package vegan. Ecologically, we expected that $\mathbf{E}$ would be related to local environmental control, $\mathbf{S}$ to within-basin spatial dynamics and $\mathbf{B}$ to biogeographic effects. 
We also ran Principal Components Analysis (PCA) based on Hellinger-transformed presenceabsence data for each organism group to visually examine breakpoints in community structure. If those breakpoints are related to among-region differences, they should be easily detectable by plotting regions using different symbols. In contrast, if the breakpoints are related to gradients in local environmental factors, they should not be related to regions. PCA based on Hellinger-transformed data was chosen among the various unconstrained ordination methods to retain comparability with the variation partitioning in RDA (see above).

\section{Testing for different metacommunity structures}

Elements of metacommunity structure (EMS) analyses were based on instructions given in Leibold and Mikkelson (2002) and Presley et al. (2010). We followed the "range perspective" in our EMS analyses (Leibold and Mikkelson 2002). Below, we describe the flow of analyses following previous studies (Leibold and Mikkelson 2002; Heino et al. 2015b, 2015c). clumping. In this analysis, prior to calculating those metrics, a raw data site-by-species presence-absence matrix for each organismal group was ordinated using reciprocal averaging (Leibold and Mikkelson, 2002). Using this ordination method, the sites having similar species composition occur close to each other and the species that have similar occurrence among the sites are located close to each other along an axis (Gauch 1982). Reciprocal averaging 
analyses may be sensitive to very rare species, and we thus ran the EMS analysis for each organismal group with either all species or without singletons (i.e. species occurring at a single site only were removed prior to the analysis).

Coherence is based on calculating the number of embedded absences (EAbs) in the ordinated matrix and then comparing the observed value to a null distribution of embedded absences (i.e. gaps in a species range) from simulated matrices (Leibold and Mikkelson 2002; Presley et al. 2010). A small number of embedded absences (i.e. EAbs is significantly lower than expected by chance) mean positive coherence, whereas a large number of embedded absences (i.e. EAbs is significantly larger than expected by chance) mean negative coherence. Significantly negative coherence thus suggests a checkerboard distribution of species, nonsignificant coherence refers to randomness, and significantly positive coherence refers to nestedness, evenly-spaced gradients, Gleasonian structure or Clementsian structure (Leibold and Mikkelson 2002). Turnover is evaluated only if coherence is positive. Turnover is measured as the number of times one species replaces (Rep) another between two sites in an ordinated matrix (Presley et al. 2010). Significant negative turnover (i.e. Rep is significantly lower than expected by chance) refers to nestedness, whereas significantly positive turnover (i.e. Rep is significantly larger than expected by chance) refers to evenly-spaced, Gleasonian or Clementsian structures (Leibold and Mikkelson 2002). Furthermore, the cases of significant positive coherence and non-significant turnover can be regarded as quasistructures (Presley et al. 2010). The evenly-spaced, Gleasonian and Clementsian metacommunity structures can be separated based on boundary clumping (Leibold and Mikkelson 2002). This metric is assessed using Morisita's dispersion index and a subsequent chi-square test comparing observed and expected distributions of range boundary locations. Index values significantly less than 1 indicate hyperdispersed range boundaries (i.e. evenlyspaced metacommunity structure), values that are not different from 1 indicate randomly 
distributed range boundaries (i.e. Gleasonian metacommunity structure), values significantly

413

414

415

416

417

418

419

420

421

422

423

424

425

426

427

428

429

430

431

432

433

434

435

greater than 1 indicate clumped range boundaries (i.e. Clementsian metacommunity

structure). Similarly, Quasi-evenly-spaced, Quasi-Gleasonian and Quasi-Clementsian

metacommunity structures can be separated by boundary clumping (Presley et al. 2010).

We assessed the significance of the index values for coherence (EAbs) and turnover (Rep) using the fixed-proportional null model, where row sums are fixed (i.e. the species richness of each site was maintained), but column marginal frequencies (i.e. species frequencies of occurrence) were considered probabilities. Random matrices were produced using the "rl" method for the fixed-proportional null model as implemented in the R package vegan (Oksanen et al. 2013). This method is the default in the $\mathrm{R}$ package we used (Dallas 2013), and it has been previously used in several other studies (e.g. Heino et al. 2015c). Although a stricter fixed-fixed null model might provide slightly different results from those of fixed-proportional null model, such fixed-fixed null model was not used because it is overly conservative and because we could not have then compared our results with those from single drainage basins (e.g. Heino et al. 2015e). We used 999 simulations to provide simulated matrices. Statistical significance of EAbs or Rep was subsequently estimated by comparing the observed index value from the original matrix to the distribution of values derived from the 999 simulated matrices. Metacommunity structure was examined for each organismal group based on axis 1 of reciprocal averaging because we were interested in the most important species compositional gradient (Gauch 1982). All EMS analyses were run using the R package metacom (Dallas 2013), with the "rl" method borrowed from the $\mathrm{R}$ package vegan (Oksanen et al. 2013).

\section{Quantifying beta diversity}


437 We quantified beta diversity following the ideas presented by Baselga (2010). We thus

438 partitioned total beta diversity (i.e. multiple-site beta diversity based on Sørensen coefficient)

439 in each data set (i.e. across three drainage basins) into turnover (i.e. multiple-site beta

440 diversity based on Simpson coefficient) and nestedness components (i.e. that resulting from

441 nestedness-related species richness differences among sites) using the function

442 “nestedbetasor” in the R package vegan (Oksanen et al. 2013).

\section{$444 \quad$ Results}

Overall, our results showed that basin identity and local environmental variables were significant predictors of variation in community structure, whereas within-basin spatial effects were typically negligible (Table 1). In half of the cases (diatoms, bryophytes, zooplankton), basin identity was a slightly better predictor of community structure compared with local environmental variables, whereas the opposite was true for the remaining three organismal groups (insects, macrophytes, fish). Both pure basin and local environmental fractions were, however, significant after accounting for the effects of the other predictor variable set $(p<0.05)$. Only for lake macrophytes were pure within-region spatial effects significant, but their pure effects were slightly smaller than those for local environmental and basin variables. All three pure components (i.e., pure environmental, pure within-region spatial and pure region identity components) were significant for macrophytes $(\mathrm{p}<0.05)$. Much of the explained variation was shared between the two or three predictor variable sets. Also, our overall RDA models explained only a small fraction of variation in community structure, varying between 10 and $20 \%$. Total variation explained or pure environmental 
fraction were not significantly related to spatial extent of the entire study regions (Spearman rank correlation, $\mathrm{p}>0.200$ ). The environmental variables selected in the RDA models were those which are often influential in aquatic metacommunity studies (Table 1). For streams, the most common environmental variable, occurring in all models, was water $\mathrm{pH}$. For lakes, lake area was selected in the models of all organismal groups.

Of the organismal groups, diatoms, insects and zooplankton showed clear regional

differences in two-dimensional PCA ordination plots (Fig. 3). This suggest that breakpoints in community composition are mainly related to among-region differences. In contrast, bryophytes, macrophytes and fish showed less clear regional separation of community composition, suggesting that potential breakpoints were related to variations in local environmental factors (Fig. 3).

All organismal groups showed high levels of beta diversity irrespective of the levels of gamma diversity and mean alpha diversity (Table 2). High beta diversity was largely attributable to the turnover component, whereas the nestedness component was rather high only for fishes. Such high levels of beta diversity were also reflected in coherent metacommunity structures, higher turnover than expected by chance and clear boundary clumping (Table 3). Hence, in the majority of the cases, the datasets fitted best with Clementsian metacommunity structures, with Quasi-Clementsian structures being found only

478 for stream bryophytes and lake zooplankton (Table 3). It was notable that the beta diversity measures or the EMS analysis were not sensitive to the exclusion of rare taxa (i.e. when singletons were removed from the analyses) (Tables 2 and 3). 
We examined three sources of variation in community structure, namely drainage basin effect, spatial effect and environmental effect, which can be translated into mechanisms related to biogeography, spatial dynamics and environmental filtering, respectively. We found that (1) mainly basin identity and local environmental factors were significant determinants of community structure in all organismal groups, whereas spatial relationships between sites were influential only for lake macrophytes. We also observed (2) that all organismal groups showed high beta diversity, turnover component in particular, across the basins (this study) and within each basin (Heino et al. 2015c), and (3) fitted best with Clementsian structures.

\section{Determinants of community structure of aquatic organisms}

Environmental control often dominates over all spatial effects on metacommunity organization (Cottenie 2005; Soininen 2014). We found support for this expectation in three of the six organismal groups (i.e. insects, macrophytes, fish), which corroborates many findings from streams (Landeiro et al. 2012; Grönroos et al. 2013; Alahuhta et al. 2015) and lakes (Cottenie et al. 2003; Alahuhta and Heino 2013; Heino 2013). These findings suggest that environmental filtering is the main mechanism structuring metacommunities (Cottenie 2005; Van der Gucht et al. 2007), at least if the spatial extent of a region under study is not very broad (Mykrä et al. 2007; Heino et al. 2015a). Although the maximum spatial extent in our datasets was more than $150,000 \mathrm{~km}^{2}$, we did not find that basin identity (i.e. the biogeographical effect) would overcome the effect of local environmental factors on the community structure of insects, macrophytes or fish. This finding may be due to two main reasons. First, environmental ranges typically increase with increasing spatial extent, thus 
providing more scope for environmental filtering provided that dispersal remains adequate (e.g. Soininen 2014). Second, in lowland regions, such as our present study area, different drainage basins may harbour rather similar biotas. This result is in contrast with findings from more topographically separated drainage basins (e.g. Hoeinghaus et al. 2007). Such small differentiation in regional faunas or floras between our drainage basins leads to apparent patterns that mainly environmental filtering drives variation in local community structure of insects, macrophytes and fish. This also suggests that biogeographic effects, such as historical influences and climatic forcing, have rather minor effects on local aquatic communities in lowland regions.

We expected that environmental conditions would overcome the effects of withinregion spatial structuring. We found clear support for this expectation for the three stream organismal groups, but lake macrophytes showed significant spatial structuring along with significant environmental effects. This might result from stronger dispersal limitation in lake organisms compared to stream organisms. However, despite being significant, spatial effects on lake macrophytes were minor at best, supporting the role of environmental filtering in driving variation in community structure. Similar studies conducted across multiple regions have found corresponding results, whereby within-region spatial effects are less important than environmental control (Declerck et al. 2011; De Bie et al. 2012; Viana et al. 2015). It is interesting to note that our study regions were of intermediate size in comparison to Declerck et al.'s (2011) wetland pond study and Viana et al.'s (2015) lake study that extended over large regions in most of western Europe, and that our findings were rather similar to those studies. This suggests some similarities across broad spatial scales when there are multiple separate regions under study.

We also predicted that basin identity would overcome the effects of local environmental factors and spatial relations within drainage basins. This prediction proved to 
be partly correct. Although basin effects were significant for all organismal groups, the amount of explained variation of pure basin effect was higher than that of local environmental variables for diatoms, bryophytes and zooplankton. It is possible that such region effects become even more important with increasing spatial extents, and previous findings at a large spatial extent have found similar effects on lake macrophytes and zooplankton (Viana et al. 2015). Our result that diatoms, bryophytes and zooplankton showed stronger basin effects than environmental effects is surprising, however, because small passively dispersing organisms or their tiny propagules should be able to follow variation in local environmental variables and cross drainage basin boundaries easily (Kristiansen 1996; De Bie et al. 2012). It is hence likely that some unmeasured, yet potentially influential environmental variables (e.g. temperature or geology) vary between the drainage basins, which translated into basin effect on community structure for diatoms, bryophytes and zooplankton. Moreover, Alahuhta et al. (2016) found that melting of ice sheet after the last ice age created variable local environmental conditions along even modest altitudinal gradient, further affecting present-day community composition. However, it would be very difficult to examine those effects further with the present data, as climatic, geological and historical (e.g. time since glaciation) conditions vary clearly among the basins, but are clearly less variable or not measurable within each basin. This means that those effects are hardly discernible from the effects of basin identity on aquatic communities.

We expected that lake organisms should be more dispersal limited than stream organisms, and thus the former should show more spatial structuring than the latter. This finding was partly supported, as none of the stream organismal groups exhibited significant within-region spatial structuring, whereas lake macrophytes and fish showed significant spatial structuring. This finding largely corroborates previous findings, where spatial structuring within small drainage basins is often negligible for headwater stream organisms 
558 (Heino et al. 2012; Landeiro et al. 2012), whereas statistically significant spatial structuring 559 has been found for some groups of lake organisms (Beisner et al. 2006; Heino 2013). This

560 pattern may be due to the fact that stream systems are more connected than lake systems,

561 which results in differences in the likelihood of dispersal limitation between lotic and lentic

562 systems. However, some studies have found that species sorting through environmental

563 heterogeneity among sites drives variation in the community structure of both riverine and

564 lake macrophytes, whereas spatial effects are negligible (Alahuhta et al. 2015). These

565 discrepancies in findings may be related to differences in spatial extent and the connectivity

566 between the sites actually used in the analyses.

Dispersal may also potentially account for biogeographical variation in community

structure. We hypothesised that small passively dispersed organisms would surpass all geographical barriers and would thus show no evidence of basin identity, whereas the opposite should be true for large actively dispersing organisms. As a related hypothesis, we expected small passive dispersers to show stronger environmental control (De Bie et al. 2012). We found at best little support for these conjectures, as all organismal groups showed a significant pure region effect, and pure environmental effects did not vary consistently between the passive and active dispersers. While such region effects might potentially be related to limited dispersal between the three regions (Viana et al. 2015), they may equally likely arise from climatic forcing on species distributions. However, as already indicated, it is almost impossible to disentangle overall basin effects and present-day climate or historical dispersal on our results because climate varies clearly among the drainage basins, but is largely invariable among sites within our small and predominantly lowland drainage basins.

581 This is a typical finding in most freshwater bacterial (e.g. Souffreau et al. 2015), phytoplankton (e.g. Nabout et al. 2009), insect (e.g. Heino et al. 2015d), macrophyte (e.g. 
583 Alahuhta and Heino 2013) and fish (e.g. Beisner et al. 2006) metacommunity studies based 584 on adjusted coefficient of determination (Peres-Neto et al. 2006) and presence-absence data 585 (Vilmi et al. 2016). There are at least five reasons for the low amount of explained variation: 586 (1) there are influential missing environmental variables, (2) modelling of dispersal routes 587 and rates is inadequate, or (3) variation in community structure just happens to be difficult to explain owing to various deterministic and stochastic factors varying simultaneously (Heino et al. 2015d). Also, (4) very low amounts of explained variation could simply emerge by chance (T. Dallas, pers. com.). Finally, (5) the low amounts of variation explained might be related to methodological difficulties in modelling high beta diversity in a dataset, which may

592 be due to multiple turnovers in species composition (see Tuomisto et al. 2012). Despite these low amounts of explained variation, we could test our hypotheses about the relative roles of environmental control, spatial effects and region constraints by basing conclusions on significance testing and additional evidence on beta diversity and metacommunity structures.

\section{Elements of metacommunity structure}

Many previous studies on metacommunity structures using the EMS analysis have found highly variable patterns, varying from random through nested to Gleasonian (i.e. where species show individualistic responses to ecological gradients) and Clementsian (i.e. where subgroups of species show similar responses to ecological gradients) structures (Leibold and Mikkelson 2002; Presley and Willig 2010; Presley et al. 2012; Dallas and Drake 2014; Heino et al. 2015c). However, many of these studies have focused on metacommunities within small regions, which might increase variability in the results (Heino et al. 2015c). 

metacommunity structures were analysed across multiple drainage basins because this potentially means crossing multiple species pools and covering large environmental gradients. On the one hand, different species pools should result in different local communities, owing to a strong regional influence on local community structure (Heino et al. 2003; Soininen et al. 2009). On the other hand, environmental gradient lengths should increase with increasing spatial extent, resulting in stronger species composition-environment correlations among sites (Vetaas and Chaudhary 1998; Soininen 2014). Although we cannot decisively distinguish between the two main drivers of Clementsian structures because, for example, different organismal groups may show different regional vs local environmental influences on breakpoints in community composition (Fig. 3), we found strong support for such Clementsian structures. This finding is similar to those in a study of bat faunas on Caribbean islands (Presley and Willig 2010), a study of beetle faunas over northern European biogeographical provinces (Heino and Alahuhta 2015), a study on riverine invertebrates of two central German drainage basins (Tonkin et al. 2015b) and a study on wetland crustacean communities in Spanish wetlands (Gascón et al. 2016). However, this finding partly disagrees with studies conducted within small regions, including the individual drainage basins incorporated in this study. Heino et al. (2015c) found that the stream and lake metacommunities of individual drainage basins showed variable (i.e. random, nested, Gleasonian, Clementsian and quasi structures) metacommunity patterns (Table 4). This suggested some degree of scale-dependency in metacommunity structures. We hence propose that Clementsian structures are common in large-scale studies of local communities, i.e., a combination of small-grained data with broad spatial extents (Beck et al. 2012; Bini et al. 2014; Dallas and Drake 2014), whereas various patterns may be detected in small-scale studies (Heino et al. 2015e; Tonkin et al. 2015). Further indirect support for Clementsian 
631

632

633

634

635

636

637

638

639

640

641

642

643

644

645

646

647

648

649

650

651

652

653

structures at large scales was provided by the high levels of beta diversity, turnover component in particular. This is because it is likely that high turnover results in Clementsian gradients rather than, for example, nested structures (Heino et al. 2015c).

\section{Conclusions}

The simple yet heuristic approach we used here is easily adaptable to situations where there are two spatial scales and two or more individual regions (e.g. drainage basins), providing a useful starting point for more sophisticated analyses of variation in community structure. We suggest that by analysing simultaneously three sources of variation, environmental (E), spatial (S) and basin effects (B), we can reveal interesting patterns and suggest some underlying processes for variation in metacommunity organization across broad biogeographic regions. Our findings also increase understanding of biogeographical patterns of community structure in aquatic environments by combining beta diversity analysis with multivariate models (i.e. variation partitioning) and general ecological pattern detection (i.e. the EMS analysis). Indeed, our findings strongly suggest that aquatic organisms typically show high levels of beta diversity and Clementsian gradients at broad spatial extents even when the focus is on local aquatic communities.

Acknowledgements. Financial support was provided by the Academy of Finland (to JH, JS). We thank Tad Dallas, Jamie Kneitel and an anonymous reviewer for comments on an earlier version of this manuscript. 
654 References

655

656

657

658

659

660

661

662

663

664

665

666

667

668

669

670

671

672

673

674

Alahuhta J, Heino J (2013) Spatial extent, regional specificity and metacommunity structuring in lake macrophytes. J Biogeogr 40:1572-1582

Alahuhta, J, Hellsten S, Kuoppala, M, Riihimäki, J (2016) Regional and local determinants of macrophyte community compositions in high-latitude lakes of Finland. Hydrobiologia, in press

Alahuhta J, Rääpysjärvi J, Hellsten S, Kuoppala M, Aroviita J (2015) Species sorting drives variation of boreal lake and river macrophyte communities. Comm Ecol 16:7685

Anderson MJ, Crist TO, Chase JM, Vellend M, Inouye BD, Freestone AL, Sanders N., Cornell HV, Comita LS, Davies KF, Harrison SP, Kraft NJB, Stegen JC, Swenson NG (2011) Navigating the multiple meanings of $\beta$ diversity: a roadmap for the practicing ecologist. Ecol Lett 14:19-28

Baselga A (2010) Partitioning the turnover and nestedness components of beta diversity. Global Ecol Biogeogr 19:134-143

Beisner BE, Peres-Neto PR, Lindström E, Barnett A, Longhi ML (2006) The role of dispersal in structuring lake communities from bacteria to fish. Ecology 87:2895-2991

Beck J, Ballesteros-Mejia L, Buchmann CM, Dengler J, Fritz SA, Gruber B, Hof C, Jansen F, Knapp S, Kreft H, Schneider A-K, Winter M, Dormann CF (2012) What's on the horizon for macroecology? Ecography 35:673-683 
675 Bini LM, Landeiro VL, Padial AA, Siqueira T, Heino J (2014) Nutrient enrichment is related

676

677 to two facets of beta diversity for stream invertebrates across the United States. Ecology 95:1569-1578

Blanchet FG, Legendre P, Borcard D (2008) Forward selection of explanatory variables. Ecology 89:2623-2632

Borcard D, Gillet F, Legendre P (2011) Numerical Ecology with R. Springer, New York.

Borcard D, Legendre P (2002) All-scale spatial analysis of ecological data by means of principal coordinates of neighbour matrices. Ecol Model 153:51-68

Borcard D, Legendre P, Drapeau P (1992) Partialling out the spatial component of ecological variation. Ecology 73:1045-1055

Clements FE (1936) Nature and Structure of the Climax. J Ecol 24:252-284

Cottenie K (2005) Integrating environmental and spatial processes in ecological community dynamics. Ecol Lett 8:1175-1182

Dallas T (2013) metacom: Analysis of the "elements of metacommunity structure". R package version 1.2. http://CRAN.R-project.org/package=metacom

Dallas T, Drake JM (2014) Relative importance of environmental, geographic, and spatial variables on zooplankton metacommunities. Ecosphere 5:art104

da Silva PG, Hernández MIM (2015) Scale-dependence of processes structuring dung beetle metacommunities using functional diversity and community deconstruction approaches. PLoS ONE 10:e0123030

De Bie T, De Meester L, Brendonck L, Martens K, Goddeeris B, Ercken D, Hampel H, Denys L, Vanhecke L, Van der Gucht K, Van Wichelen J, Vyverman W, 
Declerck SAJ (2012) Body size and dispersal mode as key traits determining metacommunity structure of aquatic organisms. Ecol Lett 15:740-747

Declerck SAJ, Coronel JS, Legendre P, Brendonck L (2011) Scale dependency of processes structuring metacommunities of cladocerans in temporary pools of High-Andes wetlands. Ecography 34:296-305

Diniz-Filho JAF, Bini LM (2005) Modelling geographical patterns in species richness using eigenvector-based spatial filters. Glob Ecol Biogeogr 14:177-185

Dray S, Pélissier R, Couteron P, Fortin MJ, Legendre P, Peres-Neto PR, Bellier E, Bivand R, Blanchet FG, De Cáceres M, Dufour AB, Heegaard E, Jombart T, Munoz F, Oksanen J, Thioulouse J, Wagner HH (2012) Community ecology in the age of multivariate multiscale spatial analysis. Ecol Monogr 82:257-275

Gascón, S, Cañedo-Argüelles M, Nebra A, Ruhí A, Rieradevall M, Caiola N, Sala J, Ibàñez C, Quintana XD, Boix D (2016) Environmental filtering determines metacommunity structure in wetland microcrustaceans. Oecologia, in press.

Gauch HG (1982) Multivariate Analysis in Community Ecology. Cambridge University Press, Cambridge

Gilbert B, Bennett JR (2010) Partitioning variation in ecological communities: do the numbers add up? J Appl Ecol 47:1071-1082

Gonçalves-Souza T, Romero GQ, Cottenie K (2014) Metacommunity versus biogeography: A case study of two groups of neotropical vegetation-dwelling arthropods. PLOS ONE 9:e115137

Göthe E, Angeler DG, Sandin L (2013) Metacommunity structure in a small boreal stream network. J Anim Ecol 82:449-458

Grönroos M, Heino J, Siqueira T, Landeiro VL, Kotanen J, Bini LM (2013) Metacommunity structuring in stream networks: roles of dispersal mode, distance type and regional environmental context. Ecol Evol 3:4473-4487

Hawkins BA, Porter EE (2003) Water-energy balance and the geographic pattern of species richness of western Palearctic butterflies. Ecol Entomol 28:678-686 
Heino J (2013) Does dispersal ability affect the relative importance of environmental control and spatial structuring of littoral macroinvertebrate communities? Oecologia 171:971-980

Heino J, Alahuhta J (2015) Elements of regional beetle faunas: faunal variation and compositional breakpoints along climate, land cover and geographical gradients. J Anim Ecol 84:427-441

Heino J, Grönroos M, Soininen J, Virtanen R, Muotka T (2012) Context dependency and metacommunity structuring in boreal headwater streams. Oikos 121:537-544.

Heino J, Melo AS, Bini LM, Altermatt F, Al-Shami SA, Angeler D, Bonada N, Brand C, Callisto M, Cottenie K, Dangles O, Dudgeon D, Encalada A, Göthe E, Grönroos M, Hamada N, Jacobsen D, Landeiro VL, Ligeiro R, Martins RT, Miserendino ML, Md Rawi CS, Rodrigues M, Roque FO, Sandin L, Schmera D, Sgarbi LF, Simaika J, Siqueira T, Thompson RM, Townsend CR (2015d) A comparative analysis reveals weak relationships between ecological factors and beta diversity of stream insect metacommunities at two spatial levels. Ecol Evol $5: 1235-1248$

Heino J, Melo AS, Siqueira T, Soininen J, Valanko S, Bini LM (2015a) Metacommunity organisation, spatial extent and dispersal in aquatic systems: patterns, processes and prospects. Freshw Biol 60:845-869

Heino J, Muotka, T, Paavola R (2003) Determinants of macroinvertebrate diversity in headwater streams: regional and local influences. Journal of Animal Ecology $72: 425-434$

Heino J, Nokela T, Soininen J, Tolkkinen M, Virtanen L, Virtanen R (2015e) Elements of metacommunity structure and community-environment relationships in stream organisms. Freshw Biol 60:973-988

Heino J, Soininen J, Alahuhta J, Lappalainen J, Virtanen R (2015c) A comparative analysis of metacommunity types in the freshwater realm. Ecol Evol 5:1525-1537

Hoeinghaus DJ, Winemiller KO, Birnbaum JS (2007) Local and regional determinants of stream fish assemblage structure: inferences based on taxonomic vs. functional groups. J Biogeogr 34:324-338 
Hortal J, Diniz-Filho JAF, Bini LM, Rodríguez MÁ, Baselga A, Nogués-Bravo D, Rangel TF, Hawkins BA, Lobo JM (2011) Ice age climate, evolutionary constraints and diversity patterns of European dung beetles. Ecol Lett 14:741-748

Jenkins DG, Ricklefs RE (2011) Biogeography and ecology: two views of one world. Proc R Soc Lond Ser B 366:2331-2335

Jocque M, Field R, Brendonck L, de Meester L (2010) Climatic control of dispersal ecological specialization trade-offs: a metacommunity process at the heart of the latitudinal diversity gradient? Glob Ecol Biogeogr 19:244-252

Kristiansen J (1996) Dispersal by freshwater algae - a review. Hydrobiologia 336:151-157

Lappalainen J, Malinen T (2002) Effects of area and location on pikeperch yields in Finnish lakes. In: Cowx IG (ed) Management and Ecology of Lake and River Fisheries. Blackwell. pp. 35-45

Landeiro VL, Bini LM, Melo AS, Pes AMO, Magnusson WE (2012) The roles of dispersal limitation and environmental conditions in controlling caddisfly (Trichoptera) assemblages. Freshw Biol 57:1554-1564

Legendre P, Borcard D, Peres-Neto PR (2005) Analyzing beta diversity: partitioning the spatial variation of community composition data. Ecol Monogr 75:435-450

Legendre P, De Cáceres M (2013) Beta diversity as the variance of community data: dissimilarity coefficients and partitioning. Ecol Lett 16:951-963

Legendre P, Gallagher ED (2001) Ecologically meaningful transformations for ordination of species data. Oecologia 129:271-280

Legendre P, Legendre L (2012) Numerical Ecology. Third Edition. Elsevier, Amsterdam

Leibold MA, Holyoak M, Mouquet N, Amarasekare P, Chase JM, Hoopes MF, Holt RD, Shurin JB, Law R, Tilman D, Loreau M, Gonzalez A (2004) The metacommunity concept: a framework for multi-scale community ecology. Ecol Lett 7:601-613

Leibold MA, Mikkelson GM (2002) Coherence, species turnover, and boundary clumping: elements of meta-community structure. Oikos 97:237-250 
Liu J, Soininen J,Han B-P, Declerck SAJ (2013) Effects of connectivity, dispersal directionality and functional traits on the metacommunity structure of river benthic diatoms. J Biogeogr 40:2238-2248

Logue JB, Mouquet N, Peter H, Hillebrand H, The Metacommunity Working Group (2011) Empirical approaches to metacommunities: a review and comparison with theory. Trends in Ecology and Evolution 26:482-491

Meynard CN, Lavergne S, Boulangeat I, Garraud L, Van Es J, Mouquet N, Thuiller W (2013) Disentangling the drivers of metacommunity structure across spatial scales. J Biogeogr 40:1560-1571

Mouquet N, Loreau M (2003) Community patterns in source-sink metacommunities. Am Nat $162: 544-557$

Mykrä H, Heino J, Muotka T (2007) Scale-related patterns in the spatial and environmental components of stream macroinvertebrate assemblage variation. Glob Ecol Biogeogr 16:149-159

Nabout JC, Siqueira T, Bini LM, Nogueira IS (2009) No evidence for environmental and spatial processes in structuring phytoplankton communities. Acta Oecologica $35: 720-726$

Ng ISY, Carr C, Cottenie K (2009) Hierarchical zooplankton metacommunities: distinguishing between high and limiting dispersal mechanisms. Hydrobiologia 619:133-143

Oksanen J, Blanchet FG, Kindt R, Legendre P, Minchin PR, O'Hara RB, Simpson GL, Solymos P, Stevens MHH, Wagner H (2013) vegan: Community Ecology Package. R package version 2.0-10. http://CRAN.R-project.org/package=vegan

Peres-Neto PR, Legendre P, Dray S, Borcard D (2006) Variation partitioning of species data matrices: estimation and comparison of fractions. Ecology 87:2614-2625

Pinel-Alloul B, André A, Legendre P, Cardille JA, Patalas K, Salki A (2013) Large-scale geographic patterns of diversity and community structure of pelagic crustacean zooplankton in Canadian lakes. Glob Ecol Biogeogr 22:784-795

Pinel-Alloul B, Niyonsenga T, Legendre P (1995) Spatial and environmental components of freshwater zooplankton structure. Écoscience 2:1-19 
813

814

815

816

817

818

819

820

821

822

823

824

825

826

827

828

829

830

831

832

833

834

835

836

837

838

839

840

Presley SJ, Cisneros LM, Patterson BD, Willig MR (2012) Vertebrate metacommunity structure along an extensive elevational gradient in the tropics: a comparison of bats, rodents and birds. Glob Ecol Biogeogr 21:968-976

Presley SJ, Higgins CL, Willig MR (2010) A comprehensive framework for the evaluation of metacommunity structure. Oikos 119:908-917

Presley SJ, Willig MR (2010) Bat metacommunity structure on Caribbean islands and the role of endemics. Glob Ecol Biogeogr 19:185-199

Rao CR (1964) The use and interpretation of principal component analysis in applied research. Sankhyā: The Indian J Stat Ser A 26:329-358

R Core Team (2013) R: A language and environment for statistical computing. R Foundation for Statistical Computing, Vienna, Austria. URL http://www.R-project.org/

Ricklefs RE, Jenkins DG (2011) Biogeography and ecology: towards the integration of two disciplines. Proc R Soc Lond Ser B 366:2438-2448

Rundle SD, Bilton DT, Foggo A (2007) By wind, wings or water: body size, dispersal and range size in aquatic invertebrates. In: Hildrew AG, Raffaelli DG, EdmondsBrown R (eds) Body size: The Structure and Function of Aquatic Ecosystems, pp. 186-209. Cambridge University Press, Cambridge

Shurin JB, Cottenie K, Hillebrand H (2009) Spatial autocorrelation and dispersal limitation in freshwater organisms. Oecologia 159:151-159

Smith TW, Lundholm JT (2010) Variation partitioning as a tool to distinguish between niche and neutral processes. Ecography 33:648-655

Soininen J (2014) A quantitative analysis of species sorting across organisms and ecosystems. Ecology 95:3284-3292

Soininen J, Heino J, Kokocinski M, Muotka T (2009) Local-regional diversity relationship varies with spatial scale in lotic diatoms. J Biogeogr 36:720-727

Soininen J, Korhonen JJ, Karhu J, Vetterli A (2011) Disentangling the spatial patterns in community composition of prokaryotic and eukaryotic lake plankton. Limnol Oceanogr 56:508-520 
Soininen J, McDonald R, Hillebrand H (2007) The distance decay of similarity in ecological communities. Ecography 30:3-12

Souffreau C, Van der Gucht K, van Gremberghe I, Kosten S, Lacerot G, Lobão LM, de Moraes Huszar VL, Roland F, Jeppesen E, Vyverman W, De Meester L (2015) Environmental rather than spatial factors structure bacterioplankton communities in shallow lakes along a $>6000 \mathrm{~km}$ latitudinal gradient in South America. Env Microbiol 17:2336-2351

Tonkin JD, Stoll S, Jähnig SC, Haase P (2015) Contrasting metacommunity structure and beta diversity in a river-floodplain system. Oikos in press

Tonkin JD, Sundermann A, Jähnig SC, Haase P (2015) Environmental controls on river assemblages at the regional scale: an application of the Elements of Metacommunity Structure framework. PLOS ONE 10:e0135450

Tuomisto H, Ruokolainen L, Ruokolainen K (2012) Modelling niche and neutral dynamics: on the ecological interpretation of variation partitioning results. Ecography 35:961-971

Van der Gucht K, Cottenie K, Muylaert K, Vloemans N, Cousin S, Declerck S, Jeppesen E, Conde-Porcuna J-M, Degans H, Vyverman W, De Meester L (2007) The power of species sorting: local factors drive bacterial community composition over a wide range of spatial scales. Proc Natl Acad Sci USA 104:20404-20409

Vetaas OR, Chaudhary R. (1998) Scale and species-environment relationships in a central Himalayan oak forest, Nepal. Plant Ecol 134:67-76

Viana DS, Figuerola J, Schwenk K, Manca M, Hobæk A, Mjelde M, Preston CD, Gornall RJ, Croft JM, King RA, Green AJ, Santamaría L (2015) Assembly mechanisms determining high species turnover in aquatic communities over regional and continental scales. Ecography in press

Vilmi, A, Karjalainen, SM, Hellsten, S, Heino, J (2016) Bioassessment in a metacommunity context: are diatom communities structured solely by species sorting? Ecol Ind 62:86-94

Vyverman W, Verleyen E, Sabbe K, Vanhoutte K, Sterken M, Hodgson DA, Mann DG, Juggins S, Van de Vijver B, Jones V, Flower R, Roberts D, Chepurnov VA, 
Kilroy C, Vanormelingen P, De Wever A (2007) Historical processes constrain patterns in global diatom diversity. Ecology 88:1924-1931

Wiens JJ (2012) Why biogeography matters: historical biogeography versus phylogeography and community phylogenetics for inferring evolutionary and ecological processes. Front Biogeogr 4:128-135 
879 Table 1. Results of variation partitioning for each organismal group. For each organismal group, the response data were Hellinger-transformed (presence-absence) site-by-species matrix. $\mathrm{E}=$ environmental effects, $\mathrm{B}=$ basin effect and $\mathrm{S}=$ within-region spatial effect. never significant for these organismal groups except for lake macrophytes and lake fishes.

\begin{tabular}{|c|c|c|c|c|}
\hline \multicolumn{5}{|c|}{ Stream diatoms } \\
\hline Fraction & Df & Adj. R2 & $\mathrm{p}$ & Variables in the model \\
\hline $\mathrm{E}$ & 3 & 0.039 & 0.001 & Moss cover, $\mathrm{pH}$, total phosphorus \\
\hline B & 2 & 0.069 & 0.001 & Dummy variable basin \\
\hline $\mathrm{E}+\mathrm{B}$ & 5 & 0.085 & 0.001 & All variables above \\
\hline $\mathrm{E} \mid \mathrm{B}$ & 3 & 0.016 & 0.002 & \\
\hline$E \cap B$ & 0 & 0.023 & & \\
\hline $\mathrm{B} \mid \mathrm{E}$ & 2 & 0.046 & 0.001 & \\
\hline U & & 0.915 & & \\
\hline \multicolumn{5}{|c|}{ Stream insects } \\
\hline Fraction & Df & Adj. R2 & $\mathrm{p}$ & Variables in the model \\
\hline $\mathrm{E}$ & 8 & 0.155 & 0.001 & $\mathrm{pH}$, shading, deciduous trees, stream width, depth, velocity, macrophytes, sand \\
\hline B & 2 & 0.132 & 0.001 & Dummy variable basin \\
\hline $\mathrm{E}+\mathrm{B}$ & 10 & 0.187 & 0.001 & All variables above \\
\hline $\mathrm{E} \mid \mathrm{B}$ & 8 & 0.055 & 0.001 & \\
\hline$E \cap B$ & 0 & 0.100 & & \\
\hline $\mathrm{B} \mid \mathrm{E}$ & 2 & 0.032 & 0.001 & \\
\hline U & & 0.813 & & \\
\hline \multicolumn{5}{|c|}{ Stream bryophytes } \\
\hline Fraction & Df & Adj. R2 & $\mathrm{p}$ & Variables in the model \\
\hline $\mathrm{E}$ & 2 & 0.049 & 0.001 & $\mathrm{pH}$, total phosphorus \\
\hline B & 2 & 0.057 & 0.001 & Dummy variable basin \\
\hline $\mathrm{E}+\mathrm{B}$ & 4 & 0.097 & 0.001 & All variables above \\
\hline $\mathrm{E} \mid \mathrm{B}$ & 2 & 0.039 & 0.002 & \\
\hline$E \cap B$ & 0 & 0.010 & & \\
\hline $\mathrm{B} \mid \mathrm{E}$ & 2 & 0.048 & 0.001 & \\
\hline $\mathrm{U}$ & & 0.903 & & \\
\hline
\end{tabular}




\begin{tabular}{|c|c|c|c|c|}
\hline \multicolumn{5}{|c|}{ Lake zooplankton } \\
\hline Fraction & Df & Adj. R2 & $\mathrm{p}$ & Variables in the model \\
\hline $\mathrm{E}$ & 2 & 0.075 & 0.010 & Water temperature, lake area \\
\hline B & 2 & 0.078 & 0.001 & Dummy variable basin \\
\hline $\mathrm{E}+\mathrm{B}$ & 4 & 0.089 & 0.001 & All variables above \\
\hline $\mathrm{E} \mid \mathrm{B}$ & 2 & 0.010 & 0.073 & \\
\hline$E \cap B$ & 0 & 0.065 & & \\
\hline $\mathrm{B} \mid \mathrm{E}$ & 2 & 0.014 & 0.020 & \\
\hline $\mathrm{U}$ & & 0.911 & & \\
\hline \multicolumn{5}{|c|}{ Lake macrophytes } \\
\hline Fraction & Df & Adj. R2 & $\mathrm{p}$ & Variables in the model \\
\hline $\mathrm{E}$ & 4 & 0.173 & 0.001 & Conductivity, secchi depth, altitude, lake area \\
\hline$S$ & 3 & 0.061 & 0.001 & MEM.15, MEM.8, MEM.2 \\
\hline B & 2 & 0.027 & 0.008 & Dummy variable basin \\
\hline $\mathrm{E}+\mathrm{S}$ & 7 & 0.189 & 0.001 & Conductivity, secchi depth, altitude, lake area, MEM.15, MEM.8, MEM.2 \\
\hline $\mathrm{E}+\mathrm{B}$ & 6 & 0.190 & 0.001 & Conductivity, secchi depth, altitude, lake area, dummy variable basin \\
\hline $\mathrm{S}+\mathrm{B}$ & 5 & 0.092 & 0.001 & MEM.15, MEM.8, MEM.2, dummy variable basin \\
\hline $\mathrm{E}+\mathrm{S}+\mathrm{B}$ & 9 & 0.207 & 0.001 & All variables above \\
\hline $\mathrm{E} \mid \mathrm{S}+\mathrm{B}$ & 4 & 0.116 & 0.001 & \\
\hline $\mathrm{S} \mid \mathrm{E}+\mathrm{B}$ & 3 & 0.017 & 0.013 & \\
\hline $\mathrm{B} \mid \mathrm{S}+\mathrm{E}$ & 2 & 0.018 & 0.004 & \\
\hline $\mathrm{E} \cap \mathrm{S}$ & 0 & 0.048 & & \\
\hline $\mathrm{S} \cap \mathrm{B}$ & 0 & -0.001 & & \\
\hline $\mathrm{E} \cap \mathrm{B}$ & 0 & 0.012 & & \\
\hline $\mathrm{E} \cap \mathrm{S} \cap \mathrm{B}$ & 0 & -0.003 & & \\
\hline $\mathrm{U}$ & & 0.793 & & \\
\hline \multicolumn{5}{|l|}{ Lake fish } \\
\hline Fraction & Df & Adj. R2 & $\mathrm{p}$ & Variables in the model \\
\hline $\mathrm{E}$ & 4 & 0.101 & 0.001 & Lake area, altitude, colour, conductivity \\
\hline S & 2 & 0.036 & 0.001 & MEM.1, MEM.12 \\
\hline $\mathrm{B}$ & 2 & 0.028 & 0.011 & Dummy variable basin \\
\hline $\mathrm{E}+\mathrm{S}$ & 6 & 0.110 & 0.001 & Lake area, altitude, colour, conductivity, MEM.1, MEM.12 \\
\hline $\mathrm{E}+\mathrm{B}$ & 6 & 0.118 & 0.001 & Lake area, altitude, colour, conductivity, dummy variable basin \\
\hline $\mathrm{S}+\mathrm{B}$ & 4 & 0.066 & 0.001 & MEM.1, MEM.12, dummy variable basin \\
\hline $\mathrm{E}+\mathrm{S}+\mathrm{B}$ & 8 & 0.128 & 0.001 & All variables above \\
\hline $\mathrm{E} \mid \mathrm{S}+\mathrm{B}$ & 4 & 0.063 & 0.001 & \\
\hline $\mathrm{S} \mid \mathrm{E}+\mathrm{B}$ & 2 & 0.011 & 0.121 & \\
\hline $\mathrm{B} \mid \mathrm{S}+\mathrm{E}$ & 2 & 0.018 & 0.037 & \\
\hline $\mathrm{E} \cap \mathrm{S}$ & 0 & 0.028 & & \\
\hline $\mathrm{S} \cap \mathrm{B}$ & 0 & -0.001 & & \\
\hline$E \cap B$ & 0 & 0.012 & & \\
\hline $\mathrm{E} \cap \mathrm{S} \cap \mathrm{B}$ & 0 & -0.001 & & \\
\hline $\mathrm{U}$ & & 0.872 & & \\
\hline
\end{tabular}




\begin{tabular}{|c|c|c|c|c|c|c|c|}
\hline \multirow[b]{2}{*}{ Organismal group } & \multirow[b]{2}{*}{ Singletons } & \multirow[t]{2}{*}{ Gamma diversity } & \multirow{2}{*}{$\begin{array}{r}\text { Alpha diversity } \\
\text { Mean }\end{array}$} & \multicolumn{4}{|c|}{ Beta diversity } \\
\hline & & & & S.D. & Sorensen & Simpson & Nested \\
\hline Stream diatoms & Yes & 305 & 50.8 & 15.5 & 0.939 & 0.916 & 0.023 \\
\hline Stream diatoms & No & 225 & 49.0 & 14.2 & 0.935 & 0.912 & 0.023 \\
\hline Stream bryophytes & Yes & 49 & 6.13 & 3.3 & 0.949 & 0.914 & 0.036 \\
\hline Stream bryophytes & No & 31 & 5.73 & 3.0 & 0.944 & 0.905 & 0.039 \\
\hline Stream insects & Yes & 203 & 28.6 & 9.86 & 0.956 & 0.938 & 0.018 \\
\hline Stream insects & No & 144 & 27.6 & 9.59 & 0.954 & 0.935 & 0.019 \\
\hline Lake macrophytes & Yes & 101 & 26.6 & 9.36 & 0.934 & 0.894 & 0.041 \\
\hline Lake macrophytes & No & 88 & 26.3 & 9.14 & 0.933 & 0.892 & 0.041 \\
\hline Lake zooplankton & Yes & 55 & 8.3 & 3.04 & 0.952 & 0.929 & 0.023 \\
\hline Lake zooplankton & No & 37 & 8.0 & 2.91 & 0.949 & 0.924 & 0.025 \\
\hline Lake fish & Yes & 25 & 12.7 & 2.88 & 0.879 & 0.770 & 0.109 \\
\hline Lake fish & No & 24 & 12.6 & 2.87 & 0.878 & 0.768 & 0.110 \\
\hline
\end{tabular}

Table 2. Multiple site beta diversity for each organismal group. Singletons were either included (yes) in or omitted (no) from the calculations of gamma, alpha and beta diversity. Total beta diversity (Sorensen) was also decomposed into turnover (Simpson) and nestedness components (Nested). S.D. = standard deviation of alpha diversity. The numbers of sites surveyed varied from 45 to 60 among the datasets. 
Table 3. Results of the elements of metacommunity structure analysis. EAbs = embedded absences, Rep = replacements, $I=$ Morisita's index,

Mean Sim = Mean index value from 999 randomisations. Q-Clementsian = Quasi-Clementsian. The numbers of sites surveyed varied from 45 to 60 among the datasets.

\begin{tabular}{|c|c|c|c|c|c|c|c|c|c|c|c|}
\hline \multirow[b]{2}{*}{ Organismal group } & \multirow[b]{2}{*}{ Singletons } & \multicolumn{3}{|l|}{ Coherence } & \multicolumn{3}{|l|}{ Turnover } & \multicolumn{3}{|c|}{ Clumping } & \multirow[b]{2}{*}{ Interpretation } \\
\hline & & EAbs & $\mathrm{p}$ & Mean Sim & Rep & $\mathrm{p}$ & Mean Sim & I & $\mathrm{p}$ & $\overline{\mathrm{df}}$ & \\
\hline Stream diatoms & Yes & 7432 & $<0.001$ & 9407 & 767451 & $<0.001$ & 272374 & 1.98 & $<0.001$ & 302 & Clementsian \\
\hline Stream diatoms & No & 5945 & $<0.001$ & 6606 & 287325 & 0.003 & 144143 & 2.14 & $<0.001$ & 222 & Clementsian \\
\hline Stream bryophytes & Yes & 709 & $<0.001$ & 1051 & 51751 & 0.669 & 45242 & 4.48 & $<0.001$ & 46 & Q-Clementsian \\
\hline Stream bryophytes & No & 501 & $<0.001$ & 656 & 35036 & 0.025 & 22932 & 1.93 & $<0.001$ & 28 & Clementsian \\
\hline Stream insects & Yes & 5988 & $<0.001$ & 8217 & 992307 & $<0.001$ & 284808 & 3.12 & $<0.001$ & 200 & Clementsian \\
\hline Stream Insects & No & 4461 & $<0.001$ & 5562 & 422762 & $<0.001$ & 151359 & 2.38 & $<0.001$ & 141 & Clementsian \\
\hline Lake macrophytes & Yes & 2325 & $<0.001$ & 3303 & 125361 & 0.001 & 63488 & 7.08 & $<0.001$ & 98 & Clementsian \\
\hline Lake macrophytes & No & 2037 & $<0.001$ & 2812 & 88138 & $<0.001$ & 44729 & 6.74 & $<0.001$ & 85 & Clementsian \\
\hline Lake zooplankton & Yes & 1427 & 0.003 & 1778 & 75124 & 0.662 & 64798 & 2.02 & $<0.001$ & 52 & Q-Clementsian \\
\hline Lake zooplankton & No & 1085 & 0.427 & 1136 & 40136 & 0.383 & 31481 & 1.69 & $<0.001$ & 34 & Random \\
\hline Lake fish & Yes & 411 & 0.003 & 518 & 7318 & 0.020 & 3722 & 2.22 & $<0.001$ & 22 & Clementsian \\
\hline Lake fish & No & 369 & $<0.001$ & 494 & 6846 & 0.006 & 3297 & 2.12 & $<0.001$ & 21 & Clementsian \\
\hline
\end{tabular}


Table 4. A comparison of elements of metacommunity structures (EMS) at the within-basin (Heino et al. 2015c; two to five different basins per organismal group) and across-basins (this study) spatial extents. Q = Quasi. The results suggest a clear shift from various different structures to Clementsian structures at large spatial extents.

Organismal group Within basins (Heino et al. 2015c) Across basins (this study)

Stream diatoms $\quad$ Gleasonian, Q-Gleasonian, Clementsian

Clementsian

Stream bryophytes Q-Gleasonian, Q-Clementsian, Clementsian

Q-Clementsian

Stream insects

Q-Gleasonian, Gleasonian, Clementsian

Clementsian

Lake macrophytes Clementsian, Q-Clementsian

Clementsian

Lake zooplankton Random, Q-nested, Q-Gleasonian

Q-Clementsian

Lake fish

Q-Nested, Q-Clementsian, Clementsian

Clementsian 
Fig. 1. Our model systems encompass three metacommunities, each with several local communities indicated by black dots (e.g. a stream site). Black arrows connecting the metacommunities denote among-region dispersal and other region effects (a). Statistical approach includes Moran's eigenvector maps, redundancy analysis (RDA), calculation of multiple site beta diversity and definition of metacommunity structures (b). B = basin effect, $\mathrm{E}=$ environmental effect and $\mathrm{S}=$ spatial effect

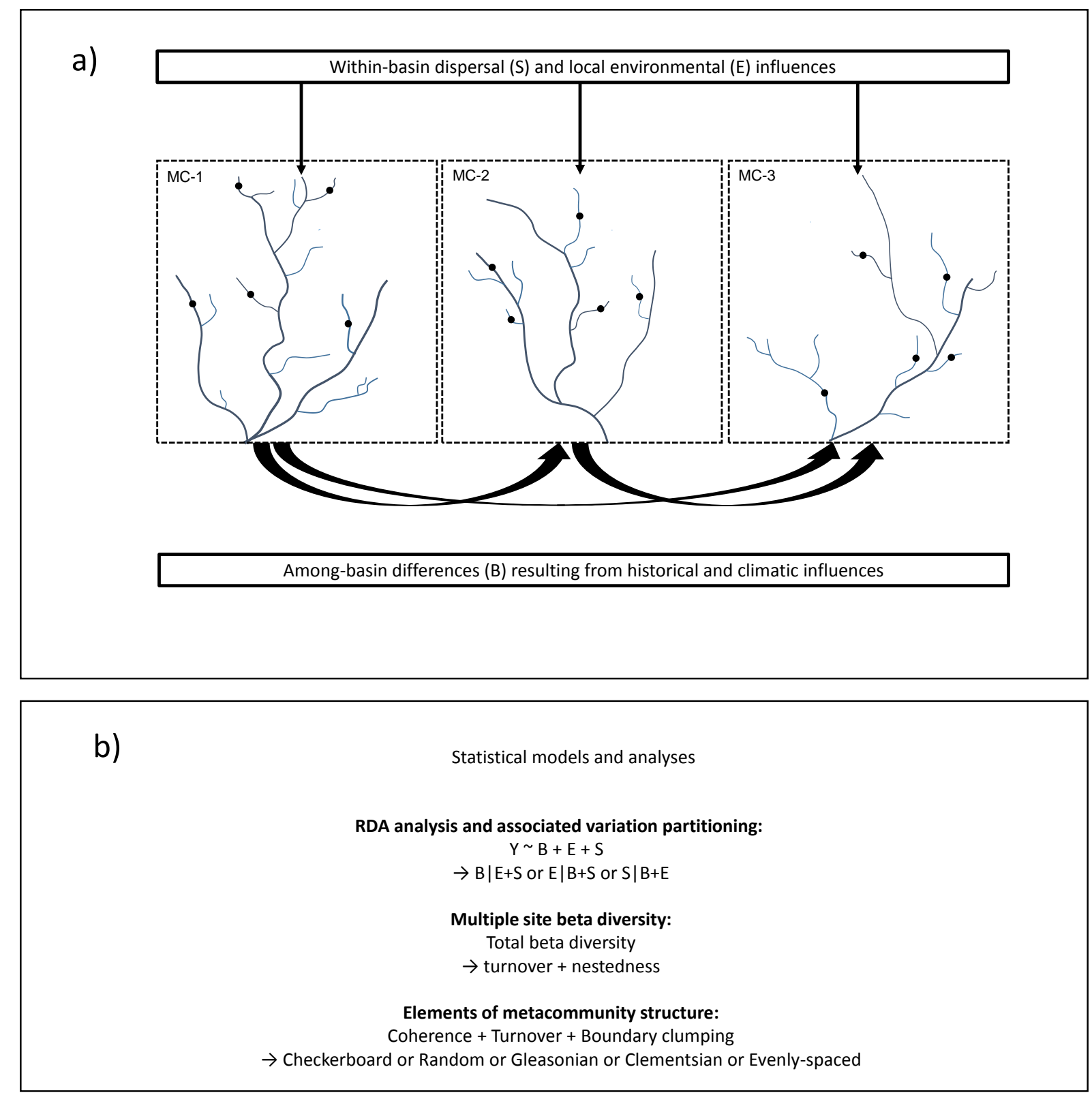


Fig. 2. Drainage basin boundaries in the datasets studied. Shown are the drainage basins sampled for diatoms and bryophytes (A), insects (B), macrophytes and fish (C) and zooplankton (D). Drainage basins are delineated to include only areas within the Finnish borders, because all surveys were done in Finland despite some drainage basins exceed national borders.
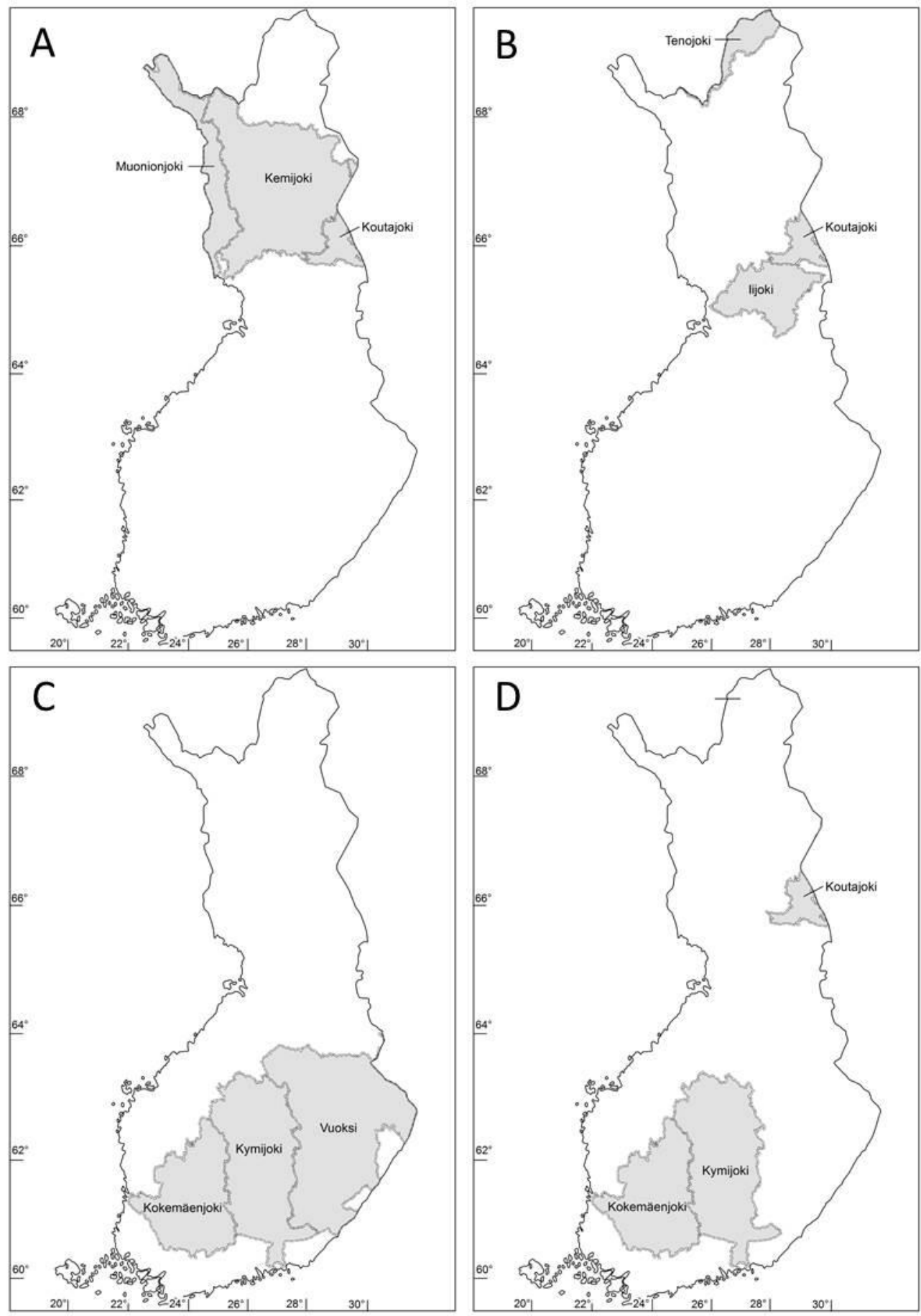
Fig. 3. PCA ordination plots for each organismal group. Different drainage basins are denoted by different symbols.
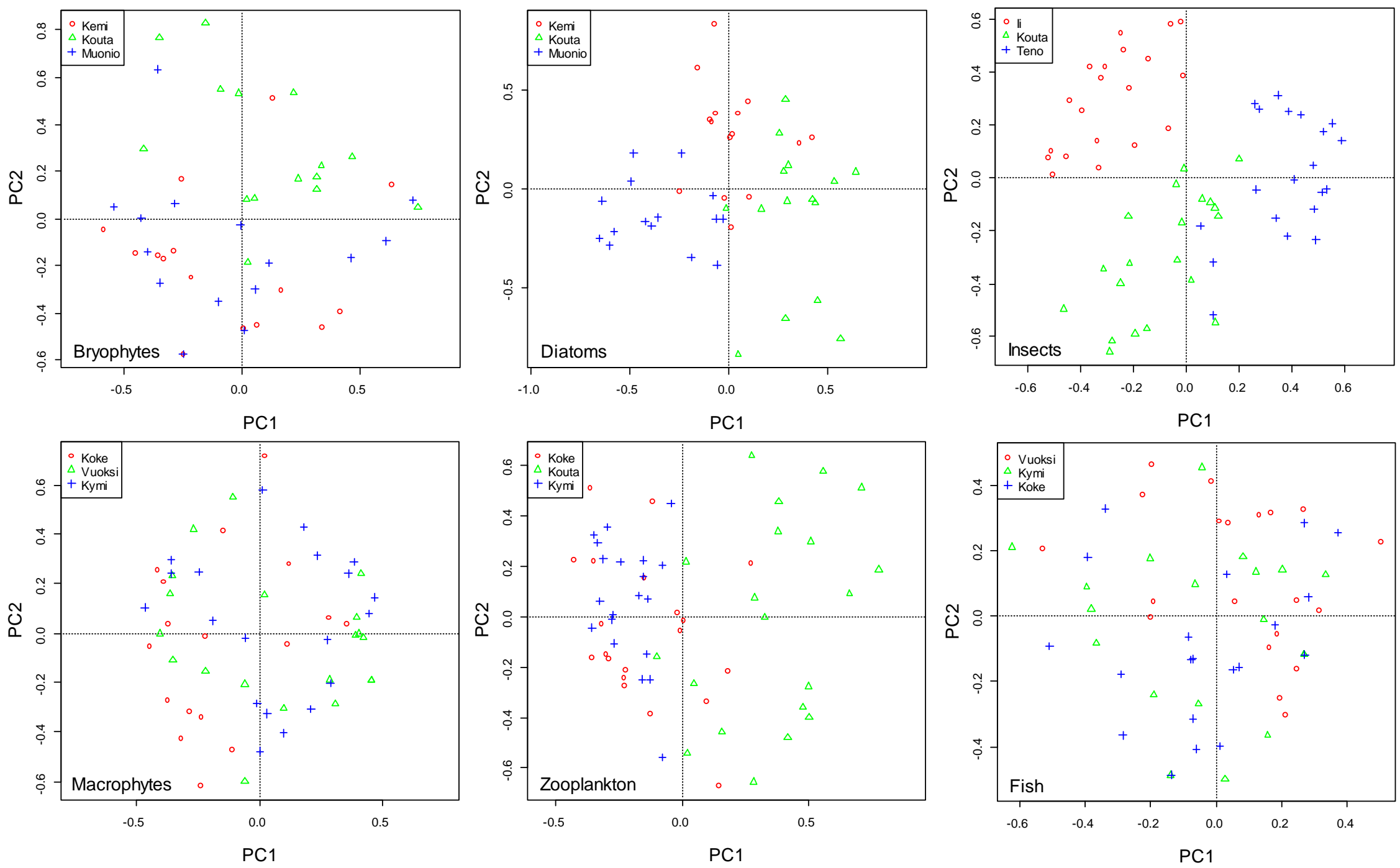
